\title{
Water and Vapor Permeability at Different Temperatures of Poly (3-Hydroxybutyrate) Dense Membranes
}

\author{
Luiz H. Poley, Marcelo G. da Silva, Helion Vargas \\ Laboratório de Ciências Físicas, UENF \\ Marcelo 0. Siqueira, Rubén Sánchez \\ Laboratório de Materiais Avançados, UENF
}

\begin{abstract}
Polyhydroxyalkanoates (PHAs) are polymers produced from renewable resources with biodegradability and biocompatibility, being therefore attractive for medical and pharmaceutical purposes. Poly (3-hydroxybutyrate) (PHB) is the most important polymer of this family by considering the biotechnology process of its synthesis. In the present study, dense films of PHB were prepared by casting from chloroform solutions $(1 \% \mathrm{~m} / \mathrm{m})$. Permeability studies with water, methanol, ethanol and n-propanol were performed using the gravimetric method at different temperatures (from $50{ }^{\circ} \mathrm{C}$ to $65^{\circ} \mathrm{C}$ ). Results provide new data on permeability coefficients of PHB membranes.
\end{abstract}

Keywords: Polymers, permeability coefficient, gravimetry.

\section{Introduction}

Sorption and diffusion of gases and organic vapors in polymers are relevant topics for both theoretical and technological interest. Careful analysis of transport properties could clarify many polymer structural aspects, which are influenced by the polymer nature, morphology, nature and density of crosslinking, crystallinity, size of permeate, temperature of preparation among others ${ }^{[1,2]}$. On the other hand, the knowledge of permeability is essential for the application of polymers as barrier materials, packages, encapsulations of electronic circuits and in the fields of reverse osmosis, controlled release of drugs and pervaporation processes ${ }^{[3]}$.

It is well accepted in literature that mass transport in polymer membranes occurs by means of a solution diffusion process ${ }^{[1,4]}$. In the diffusion of gases and vapors, crystallites are often considered to be impermeable and there are some differences between semicrystalline and rubbery polymers with respect to diffusion and permeation, most of them based on the free volume content and chain mobility ${ }^{[5]}$. Experimental data have been generally described using Fick's law of diffusion, but some deviations have been reported and described through non-Fickian mechanisms, the sigmoidal sorption and the two-step model ${ }^{[6]}$. Classical sorption experiments involve the monitoring of membrane weight gain in function of time, but alternative methodologies have also been proposed $\mathrm{d}^{[7,8]}$.

Over the last decade, the development of biodegradable materials arises as a promising solution to the problem of urban waste. Among the various ecological materials, the family of polyhydroxyalkanoates (PHAs) appears as one of the most important. They comprise a family of polyesters produced by many bacteria using renewable resources ${ }^{[9]}$. The most studied and important member of this family of polymers is the PHB, first detected as inclusions in bacteria by Lemoigne in $1926^{[10]}$.

Poly (3-hydroxybutyrate) (PHB) is a thermoplastic with a glass transition temperature slightly above $0{ }^{\circ} \mathrm{C}$ and melting point at about $180^{\circ} \mathrm{C}$. It is a biocompatible material suitable for agricultural and medical applications and for food packaging ${ }^{[1]}$. An improvement of PHB properties can be achieved by copolimerization with poly (3-hydroxyvalerate) (PHV) and by physical blending with biodegradable and non-biodegradable polymers ${ }^{[12]}$. However, there is a lack of information of the transport properties of PHB. Thus, the objective of the present study is to investigate permeability of membranes of poly (3-hydroxybutyrate) towards water and alcohol.

\section{Experimental}

\section{Materials}

PHB used in this work was obtained from Aldrich Chemical Co. with $M_{n}=87,000$ Da. The purification of the polymer was performed by dissolution in chloroform and precipitation in methanol.

\section{Sample preparation}

Films of PHB were prepared by casting from chloroform solution $(1 \% \mathrm{~m} / \mathrm{m})$ in a $15 \times 22 \mathrm{~cm}$ glass plate. Evaporation took place in a closed glass chamber kept at $20^{\circ} \mathrm{C}$. The

Autor para correspondência: Luiz H. Poley, Laboratório de Ciências Físicas, Centro de Ciência e Tecnologia, UENF, Av. Alberto Lamego 2000 - Pq. Califórnia, CEP: 28015-620, Campos dos Goytacazes, RJ. E-mail: poley@uenf.br. 
chamber has a small outlet (1cm ID) to control the vapor solvent flow into air. These procedures impose a careful control of evaporation rate to obtain a homogeneous dense film. After complete evaporation of solvent, each film was stored at atmosphere conditions during $24 \mathrm{~h}$ to complete crystallization process. Thickness $(0,05 \mathrm{~mm})$ was obtained from the average of 20 measures for each film using a conventional micrometer.

\section{Membrane crystallinity}

Membrane crystallinity was determined from X-ray diffraction analysis. A Seifert-FPM model URD65 X-ray generator with a Ni filtered $\mathrm{Cu} K \alpha$ radiation $(\lambda=0.1542 \mathrm{~nm})$ was used. Scans were recorded in the range $5^{\circ}-40^{\circ}$ at a scan speed of $0.01^{\circ}$ and an exposure time of $10 \mathrm{~s}$. Each peak of diffractogram was fitted to a Gaussian curve. The amorphous region of the diffractogram was also fitted by to a Gaussian curve. The crystallinity degree was calculated using equation 1 :

$$
X_{C}=\frac{\left(A_{T}-A_{A}\right)}{A_{T}}
$$

where $A_{T}$ denotes the total area of the diffractogram and $A_{A}$ denotes the area corresponding to the amorphous region.

\section{Thermal analysis}

Thermal characterization of PHB membranes were performed in a Calorimeter model DSC- 2010, from TA instruments. Indium was used as calibration reference. Approximately $10 \mathrm{mg}$ of membranes were encapsulated in aluminum pans and heated from -40 to $200^{\circ} \mathrm{C}$, at $20^{\circ} \mathrm{min}^{-1}$. The melting temperature, the glass transition temperature and the enthalpy of fusion were determined. The zero enthalpy of fusion for the current polymer is $163 \mathrm{~J} / \mathrm{g}^{[13]}$.

\section{Surface morphology studies}

The upper surface and the cross section of membranes were studied using a Zeiss 692 instrument. The cross section was exposed by fracture in liquid nitrogen and samples were prepared with double face graphite adhesive and sputter coated with approximately $20 \mathrm{~nm}$ of Pd-Au.

\section{Permeability measurements}

Permeation experiments with water, methanol, ethanol and $\mathrm{n}$-propanol were performed on a small bottle (similar to the Payne cup specially designed to permeation studies ${ }^{[14]}$ ) in which a small amount of liquid $(0.24 \mathrm{~g})$ was sealed with film and hermetic closed with an aluminum ring. The bottle was put on a moisture analyser (Mettler Toledo model HR73), which can register the weight loss of the bottle at selected temperatures at each 2 minutes. Experiments were performed at $50^{\circ} \mathrm{C}, 55^{\circ} \mathrm{C}, 60^{\circ} \mathrm{C}, 65^{\circ} \mathrm{C}$ and, in the case of water, also at $30^{\circ} \mathrm{C}$. Temperatures were previously adjusted in moisture analyzer and kept constant throughout the experiment. Measures were performed in triplicate and the mean value was chosen as representative of permeability coefficient.

The transport of mass through membranes occurs in accordance with Fick's Law, equation 2, which establishes that the flux of permeate through the membrane is proportional to the concentration gradient:

$$
J=-D \frac{\partial C}{\partial x}
$$

where $\mathrm{J}$ is the mass flux per unit area, $\mathrm{D}$ is the diffusion coefficient and $\mathrm{C}$ is the concentration.

Assuming that $\mathrm{D}$ is independent of concentration and that the Henry's Law is applied (both assumptions are valid at low concentrations of permeate), the permeation rate after the establishment of steady state flux can be written $a^{[4]}{ }^{[4}$ :

$$
\frac{L Q}{P_{V}-P_{E X T}}=D H\left(t-\frac{L^{2}}{6 D}\right)
$$

In the expression above, $\mathrm{Q}$ is the mass flux, $\mathrm{H}$ is Henry's constant, $\mathrm{L}$ is the membrane thickness and $\mathrm{P}_{\mathrm{v}}$ and $\mathrm{P}_{\text {ext }}$ are the vapor pressure and external pressure of the permeate, respectively (in the case of organic vapors, $\mathrm{P}_{\text {ext }}$ is assumed to be zero). The product DH defines the permeability coefficient, according to the nomenclature described by Koros et al ${ }^{[15]}$. Therefore the slope of the curve obtained from the graphic representation of mass versus time, at steady state conditions, provides permeability coefficient.

\section{Results and Discussion}

Figure 1 presents X-ray diffractogram of PHB membranes. The solid lines in this figure represents Gaussians curves used for fitting the peaks. Crystallinity of PHB films obtained from $\mathrm{X}$-ray diffraction was $65 \% \pm 1 \%$. This high value of crystallinity is related to the isotactic arrangement of PHB monomers in the polymer chains ${ }^{[16]}$.

DSC curve of PHB is shown in Figure 2. Glass transition, melting temperature and enthalpy of fusion values were $2.4{ }^{\circ} \mathrm{C}, 176{ }^{\circ} \mathrm{C}$ and $101 \mathrm{~J} / \mathrm{g}$, respectively. The enthalpy of fusion was obtained from the area of the endothermic peak as described in literature ${ }^{[17]}$

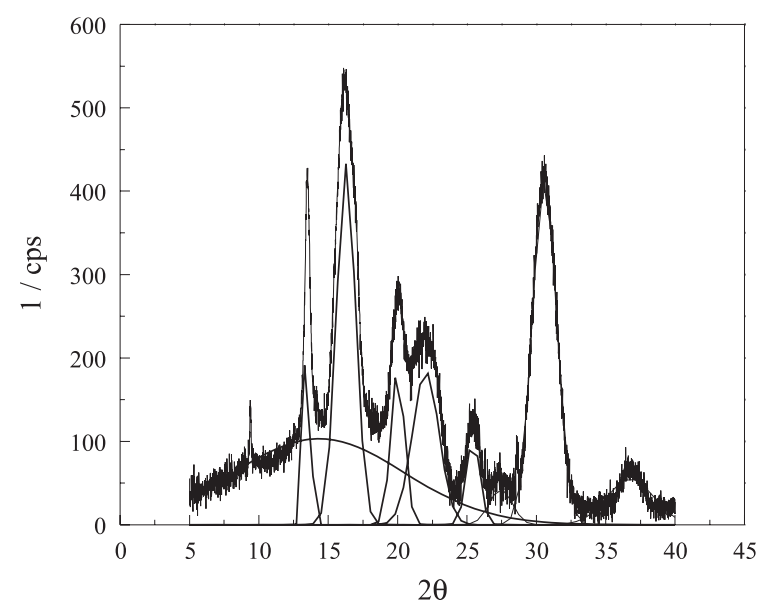

Figure 1. X-Ray Diffractogram for PHB. 


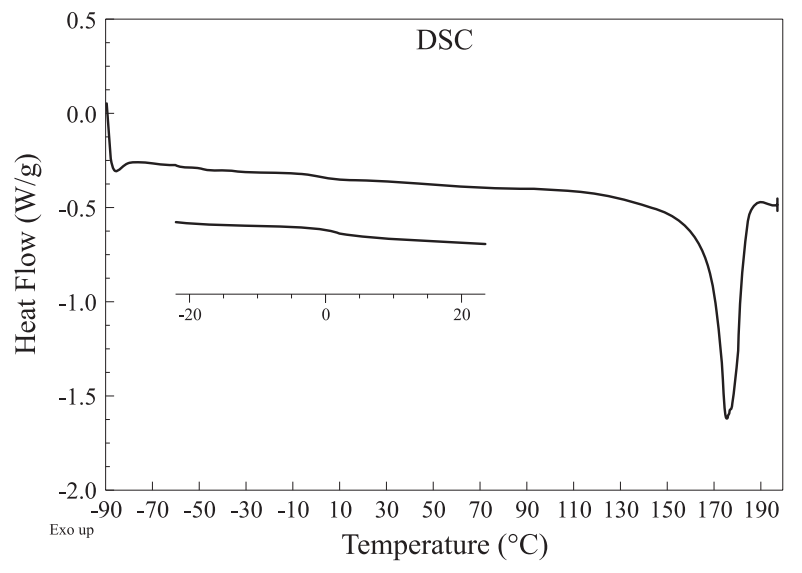

Figure 2. DSC curve for PHB. In the secondary scale, glass transition is detailed.
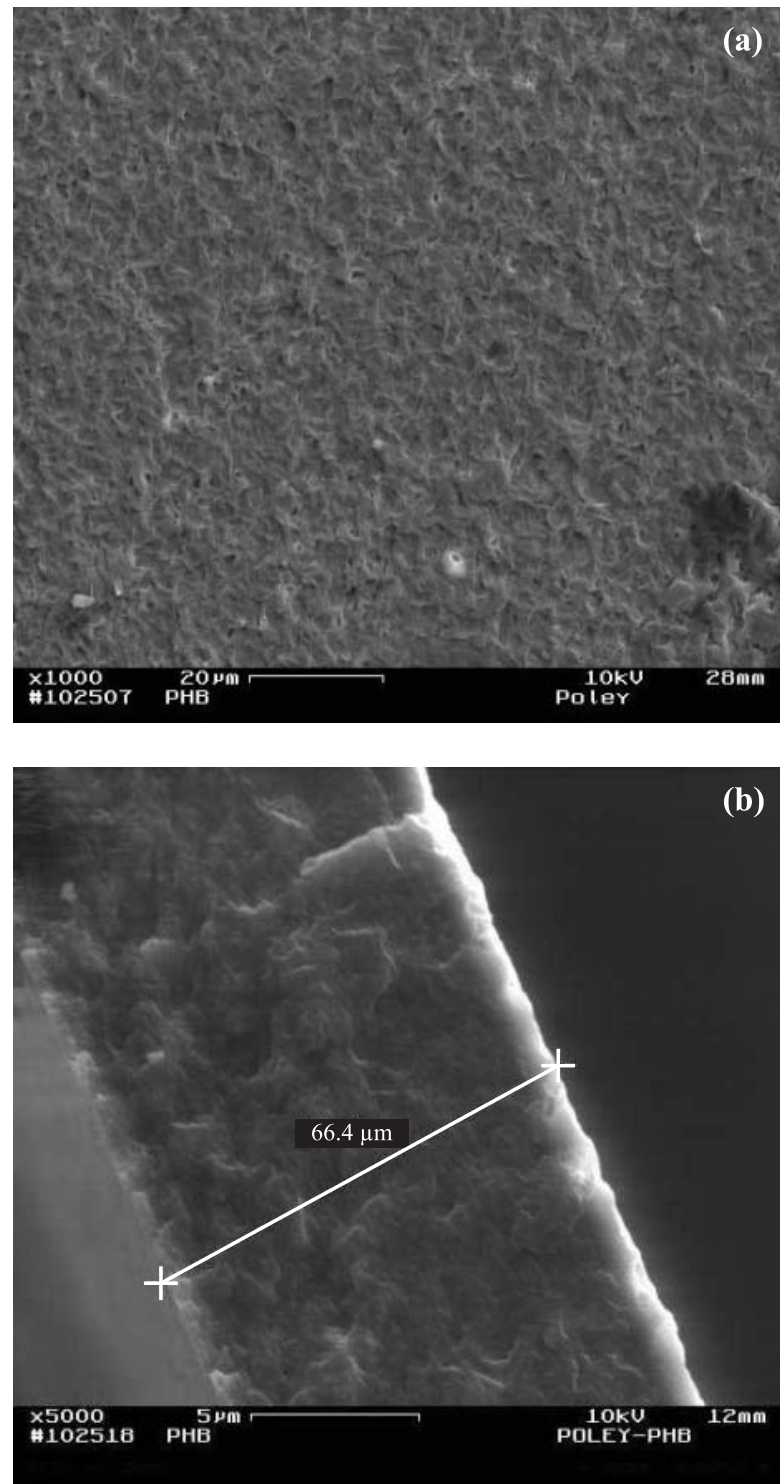

Figure 3. Scanning electron microscopy images of the upper surface (a) and the lateral surface (b) of PHB membranes.

Figure 3 presents SEM micrographs of the upper and lateral surfaces of PHB membranes. The upper surface (Figure 3a)
Table 1. Permeability coefficients in Barrer unit for PHB membranes studied in this work.

\begin{tabular}{ccccc}
\hline Temperature & Methanol & Ethanol & N- propanol & Water \\
\hline $30{ }^{\circ} \mathrm{C}$ & - & - & - & $520 \pm 20$ \\
$50{ }^{\circ} \mathrm{C}$ & $1130 \pm 60$ & $890 \pm 50$ & $480 \pm 20$ & $750 \pm 40$ \\
$55^{\circ} \mathrm{C}$ & $1590 \pm 80$ & $900 \pm 50$ & $520 \pm 20$ & $990 \pm 50$ \\
$60^{\circ} \mathrm{C}$ & $1640 \pm 80$ & $920 \pm 50$ & $530 \pm 20$ & $1050 \pm 50$ \\
$65^{\circ} \mathrm{C}$ & $2090 \pm 100$ & $1230 \pm 60$ & $590 \pm 30$ & $1900 \pm 100$ \\
\hline
\end{tabular}

exhibits a rough structure with defects and voids, typical of cast prepared films, also observed in previous works ${ }^{[18,19]}$. In the lateral surface (Figure $3 \mathrm{~b}$ ) no pore were observed, characterizing the membranes as dense and validating the theoretical development used for determining membrane permeability.

Figures 4-7 present experimental data, permeated mass as function of time, obtained from permeation gravimetric studies. At steady state conditions, permeation through the membranes occurs at constant rates. These data allowed permeability coefficient to be determined using equation 3, from the slope of the linear fitting. Values are shown in Table 1 in Barrer units: $10^{-10} \mathrm{~cm}^{3}(\mathrm{STP}) \cdot \mathrm{cm} \cdot \mathrm{cm}^{-2} \cdot \mathrm{Hg}^{-1}$.

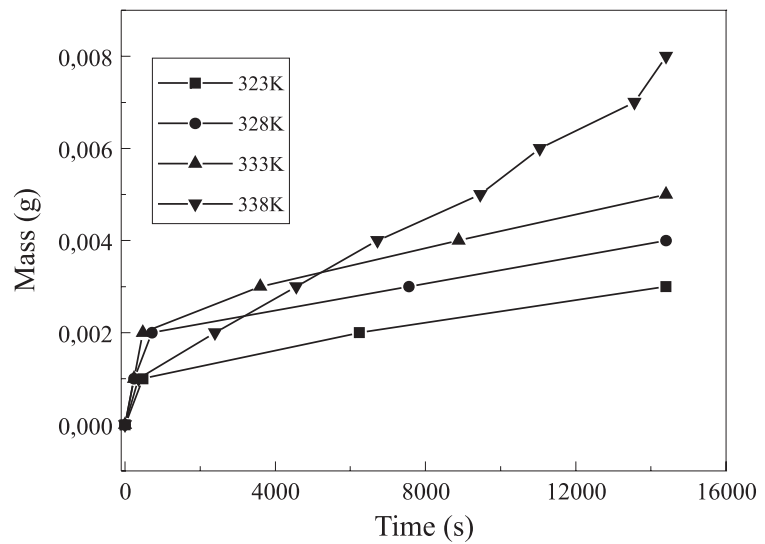

Figure 4. Permeability plot for water at different temperatures.

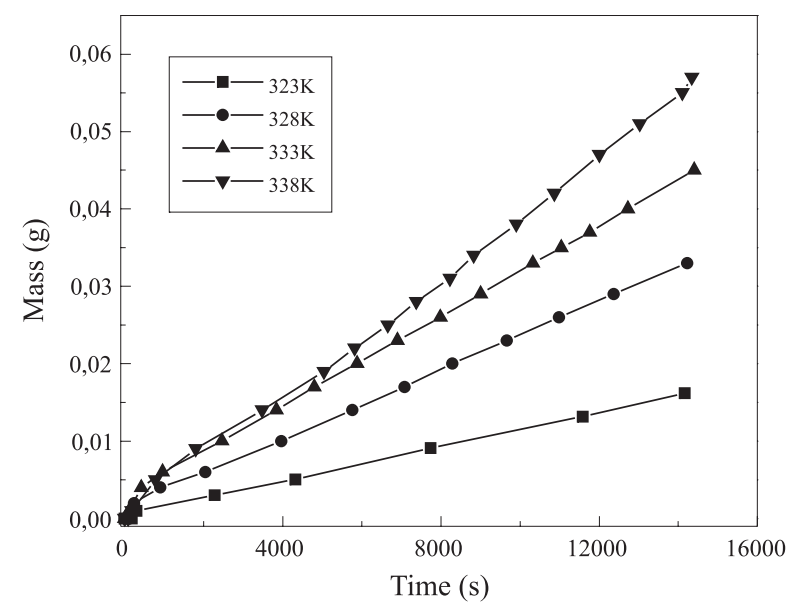

Figure 5. Permeability plot for methanol at different temperatures. 


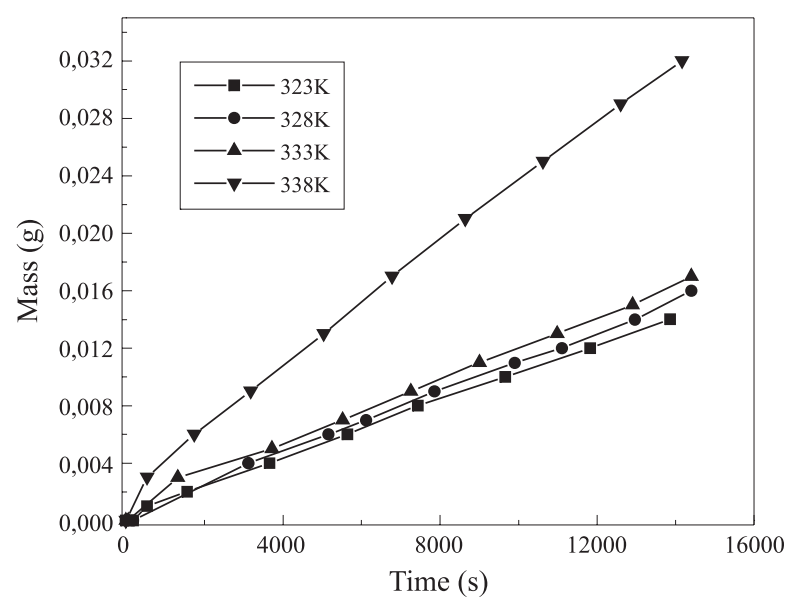

Figure 6. Permeability plot for ethanol at different temperatures.

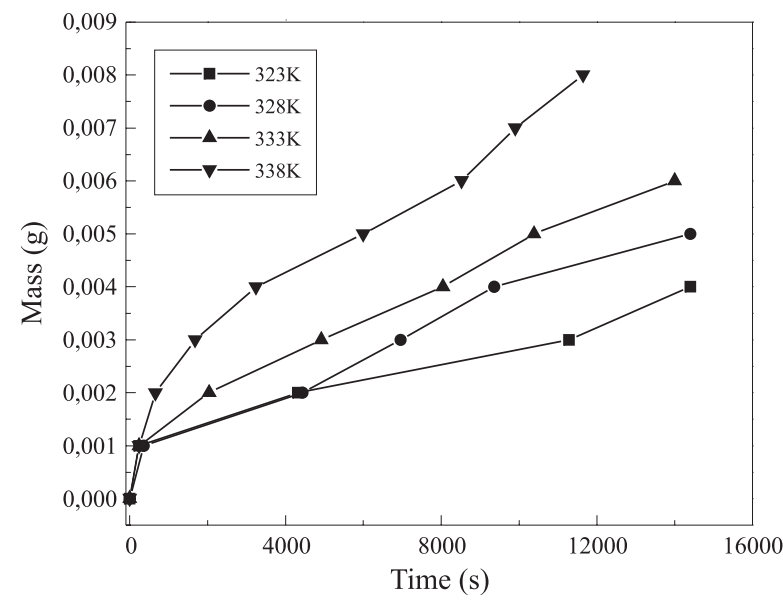

Figure 7. Permeability plot for n-propanol at different temperatures.

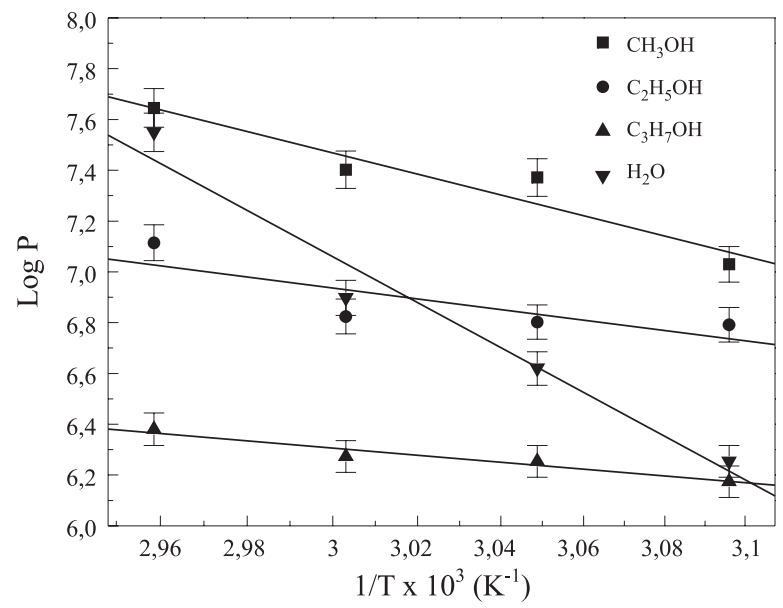

Figure 8. Arrhenius plot obtained from the dependence of $\log \mathrm{P}$ on $1 / \mathrm{T}$ of permeates studied in this work.

The permeability coefficient obtained for water vapor at $30{ }^{\circ} \mathrm{C}$ agrees with the value reported by Miguel and coworkers for PHB membranes also prepared by casting process $^{[20]}$. In the case of organic gases, permeability coefficients decreased in one order of magnitude from methanol to n-propanol, which reflects the influence of the size of permeate, since diffusion of larger molecules require
Table 2. Activation energy values of $\mathrm{PHB}$ membranes calculated from Arrhenius relation.

\begin{tabular}{cc}
\hline Permeate & Activation Energy $(\mathbf{K J} / \mathbf{m o l})$ \\
\hline Water & $75.4 \pm 10$ \\
Methanol & $34.1 \pm 8$ \\
Ethanol & $17.9 \pm 5$ \\
n-Propanol & $11.6 \pm 5$ \\
\hline
\end{tabular}

larger sites which are less probable to occur in the polymer matrix. With water, despite of molecular size, permeability coefficients were lower than those obtained for methanol at all temperatures investigated. This fact may be due to the occurrence of interactions between diffusing molecules and polymer matrix, reported by previous works in sorption experiments ${ }^{[21,22]}$, which pointed out the presence of immobilized water molecules in sorption centers in the polymer, due to affinity between water molecules and polar carbonyl groups of PHB macromolecules.

For all permeates studied, permeability coefficients increased with temperature, which is related to the increase in free volume of polymer as a result of an increase in the molecular motion. Applying Arrhenius equation to experimental data, activation energy of permeation, $E_{P}$ was calculated as follows (equation 4):

$$
P=P_{0} e^{-\frac{E_{P}}{R T}}
$$

where $\mathrm{P}$ represents permeability coefficient and $\mathrm{P}_{0}$ is a pre exponential factor. By plotting the logarithm of $\mathrm{P}$ versus $1 / \mathrm{T}$, activation energy can be determined from the slope of the linear fitting (Figure 4). Results are presented in Table 2. In the case of water, activation energy of PHB membranes is similar to those presented by other semicrystalline polymers such as isotactic polypropylene ${ }^{[5]}$. This high value also suggests the existence of interactions between water molecules and polymer matrix, as mentioned above. For the other permeates, values agree in order of magnitude with those presented in literature for samples of poly(vinyl chloride) and polystyrene ${ }^{[23]}$.

Activation energy values of Table 2 decrease with increasing size of permeate. Some authors reported similar behavior in the permeation of hydrocarbons in some polymeric membranes ${ }^{[24,25]}$. Focusing attention on the nature of permeate, it suggests that permeation of alcohols through PHB membranes is more influenced by the aliphatic chain than by the hydroxyl group, whose interaction with polymer molecules is very strong in the case of water ${ }^{[21]}$. This fact represents a deviation from the predictions of some theoretical models of diffusion in polymers and until now it is not completely understood ${ }^{[4]}$.

\section{Conclusion}

Permeability coefficients of PHB membranes prepared by casting were determined using gravimetric techniques for water 
and organic vapors at different temperatures of measurement. A value of 520 Barrer at a temperature of $30{ }^{\circ} \mathrm{C}$ was found for water. The permeability for organic vapors decreases as the size of the molecules increases. Using Arrhenius model, activation energies of permeation were evaluated. Water has the highest activation energy $(75.4 \mathrm{KJ} / \mathrm{mol})$ when compared to the other organic permeates studied in this work.

\section{Acknowledgments}

This work was supported by CNPq and CAPES.

\section{References}

1. Naylor, T. Comprehensive Polymer Science, Vol. 2. Pergamon Press, New York (1989).

2. George, S. C. \& Thomas, S. - Prog. Polym. Sci. 26 p. 985 (2001).

3. Sagiv, A. - J. Membrane Sci. 199 p.125 (2002).

4. Neogi, P. - Diffusion in Polymers, Marcel Dekker, New York (1996).

5. Hedenqvist, M. \& Gedde, U. W. - Prog. Polym. Sci. 21 p.299 (1996).

6. Huang, S. J.; Durning, C. J. \& Freeman - J. Membrane Sci. 143 p.1 (1998).

7. Musto, P.; Mascia, L.; Ragosta G.; Scarinzi, G. \& Villano, P. - Polymer 41 p.564 (2000).

8. Pekcan, O. \& Ugur, S. - Polymer 41 p.7531 (2000).

9. Anderson A. J. \& Daves, E. A. - Microbial Rev 54 p.450 (1990)

10. Lemoigne, M. - Ann Inst Pasteur 41 p.148 (1927).

11. Holmes P. A. - Phys. Technol. 16 p.32 (1985).
12. Miguel O.; Egiburu, J. L. \& Iruin, J. J. - Polymer 42 p.953 (2001).

13. Barham, P.J. \& Keller, A. - J. Polym. Sci. Poly. Phys. 24 p. 69 (1986).

14. Guo, C. J.; De Kee, D. \& Harrison, B. - J. Appl Polym Sci 56 p.823 (1995).

15. Koros, W. J.; Ma, Y. H. \& Shimidzu, T. - J. Membrane Sci. 120 p.149 (1996).

16. Skrbic, Z. \& Divjakovic, V. - Polymer 37 p.505 (1996).

17. Haines, P. J. - Thermal Methods of Analysis: Principles, applications and problems. Champman \& Hall, (1995).

18. Galego, N.; Miguens, F. C. \& Sánchez, R. - Polymer 43 p.3109 (2002).

19. Mas, A.; Jaaba, H.; Sleds, J. \& Schue, F. - Eur. Polym. J. 32 p.435 (1996).

20. Miguel, O.; Fernandez-Berridi, M. J. \& Iruin, J. J. - J. Appl. Polym. Sci. 73 p.1849 (1997).

21. Miguel, O. \& Iruin, J. J. - J. Appl Polym Sci 73 p.455 (1999)

22. Iordanskii, A. L.; Kamaev, P. P. \& Zaikov, G. E J. Appl Polym Sci 73 p.981 (1999).

23. Berens, A. R. \& Hopfenberg, H. B. - J. Membrane Sci. 10 p.283 (1982).

24. Aminabhavi, T. M. \& Phayde, H. T. - Polymer 36 p.1023 (1995).

25. Kumar, S. A.; Thomas, S. \& Kumaran, M. G. - Polymer 38 p.4629 (1997).

Enviado: 22/01/04

Reenviado: 29/11/04

Aprovado: 01/12/04 